Supporting Information

\title{
Tailor-Made Semiconducting Polymers for Second Near-Infrared Photothermal Therapy of Orthotopic Liver Cancer
}

Tingting Sun,,$^{\dagger}$ Jinfeng Han, ${ }^{\dagger}$ Shi Liu,,$^{\dagger}$ Xin Wang,,+ Zhi Yuan Wang, ${ }^{*}+$ and Zhigang $X i e^{*, \dot{Y}}$

†State Key Laboratory of Polymer Physics and Chemistry, Changchun Institute of Applied Chemistry, Chinese Academy of Sciences, 5625 Renmin Street, Changchun 130022, P. R. China

Department of Thyroid Surgery, The First Hospital of Jilin University, 71 Xinmin Street, Changchun 130021, P. R. China 


\section{Contents:}

\section{Materials and Characterization}

\section{Supporting Figures}

Figure S1. ${ }^{1} \mathrm{H}$ NMR spectrum of TT-2Sn.

Figure S2. ${ }^{1} \mathrm{H}$ NMR spectra and GPC results (inset) of a) P1, b) P2, c) P3 and d) P4.

Figure S3. FTIR spectra of P1-P4.

Figure S4. The standard curve of P3 in THF.

Figure S5. Changes of the diameters of NPs in a) water and b) PBS containing $10 \%$ FBS as a function of time measured by DLS.

Figure S6. Photothermal conversion behavior of NPs at various concentrations under $808 \mathrm{~nm}$ laser irradiation $\left(1.0 \mathrm{~W} \mathrm{~cm}^{-2}\right)$.

Figure S7. Photothermal conversion behavior of NPs $\left(10 \mu \mathrm{g} \mathrm{mL}^{-1}\right)$ under $1064 \mathrm{~nm}$ laser irradiation by varying power densities $\left(0.54-1.96 \mathrm{~W} \mathrm{~cm}^{-2}\right)$.

Figure S8. a) The photothermal response of NPs in water $\left(30 \mu \mathrm{g} \mathrm{mL}^{-1}\right)$ with laser irradiation (808 nm, $\left.1.0 \mathrm{~W} \mathrm{~cm}^{-2}, 10 \mathrm{~min}\right)$ and then the laser was shut off. b) Linear time data versus $-\operatorname{Ln} \theta$ obtained from the cooling period of a).

Figure S9. a) The photothermal response of NPs in water $\left(20 \mu \mathrm{g} \mathrm{mL}^{-1}\right)$ with laser irradiation (1064 nm, $\left.1.0 \mathrm{~W} \mathrm{~cm}^{-2}, 10 \mathrm{~min}\right)$ and then the laser was shut off. b) Linear time data versus $-\operatorname{Ln} \theta$ obtained from the cooling period of a).

Figure S10. Temperature variations of NPs $\left(20 \mu \mathrm{gL}^{-1}\right)$ in water under $1064 \mathrm{~nm}$ laser irradiation over 6 cycles of heating and natural cooling.

Figure S11. Relative temperature changes of NPs in water upon exposures to 808 and $1064 \mathrm{~nm}$ laser under chicken tissues of varying thicknesses $(0,2,4,6$ and $8 \mathrm{~mm})$.

Figure S12. Ex vivo IR images of heart, liver, spleen, lung and kidney of mice 
injected with NPs intravenously $\left(2.87 \mathrm{mg} \mathrm{kg}^{-1}\right)$ for different time under laser irradiation $\left(1064 \mathrm{~nm}, 1.0 \mathrm{~W} \mathrm{~cm}^{-2}\right)$.

Figure S13. Relative temperature changes of heart, liver, spleen, lung and kidney of mice injected with NPs intravenously $\left(2.87 \mathrm{mg} \mathrm{kg}^{-1}\right)$ for different time under laser irradiation (1064 nm, $\left.1.0 \mathrm{~W} \mathrm{~cm}^{-2}\right)$.

Figure S14. IR images of mice without NPs injection under 808 or $1064 \mathrm{~nm}$ laser irradiation $\left(1.0 \mathrm{~W} \mathrm{~cm}^{-2}\right)$.

Figure S15. Changes in body weight of tumor-bearing mice after various treatments.

Figure S16. a) CT imaging and b) tumor volumes of mice after different treatments for 4,8 and $17 \mathrm{~d}$.

Figure S17. Photos of mice after treatments for $17 \mathrm{~d}$. The red circles indicate the mice with liver ascites.

Figure S18. Survival Rates of tumor-bearing mice after various treatments. 


\section{Materials and Characterization}

F-127 was purchased from Shanghai yuanye Bio-Technology Co., Ltd. BBT-2Br and BTT-2Sn were purchased from SunaTech Inc.. Cell viability (live-dead cell staining) assay kit and Hoechst 33258 were purchased from Jiangsu KeyGEN Biotechnology Co., Ltd. 0.25\% Trypsin-EDTA, Phenol Red(modified) was purchased from Dalian Meilun Biotechnology Co., Ltd. The other chemicals were used as obtained commercially. Analytical balance (XS105DU) and Rainin Pipettes from METTLER TOLEDO were used to quantify solid and liquid respectively. ${ }^{1} \mathrm{H}$ NMR spectra were measured with Bruker Avance NMR spectrometer (400 MHz). Molecular weight of the polymers were measured by gel permeation chromatography (GPC) on a TOSOH HLC-8220 SEC instrument (column: Super HZM-H $\times 3$ ) at $40{ }^{\circ} \mathrm{C}$ using tetrahydrofuran (THF) as eluent. Elemental analysis was performed on a Bio-Rad elemental analyzer. The absorption spectra and FTIR spectra were obtained from a UV-3600 UV-vis-NIR spectrophotometer (Shimadzu) and Nicolet Impact 410 FTIR spectrometer respectively. TEM and DLS results of NPs were determined by JEOL JEM-1011 electron microscope (acceleration voltage of $100 \mathrm{kV}$ ) and Malvern Zeta-sizer Nano. CLSM images were obtained from a Zeiss LSM 700 (Zurich, Switzerland). 


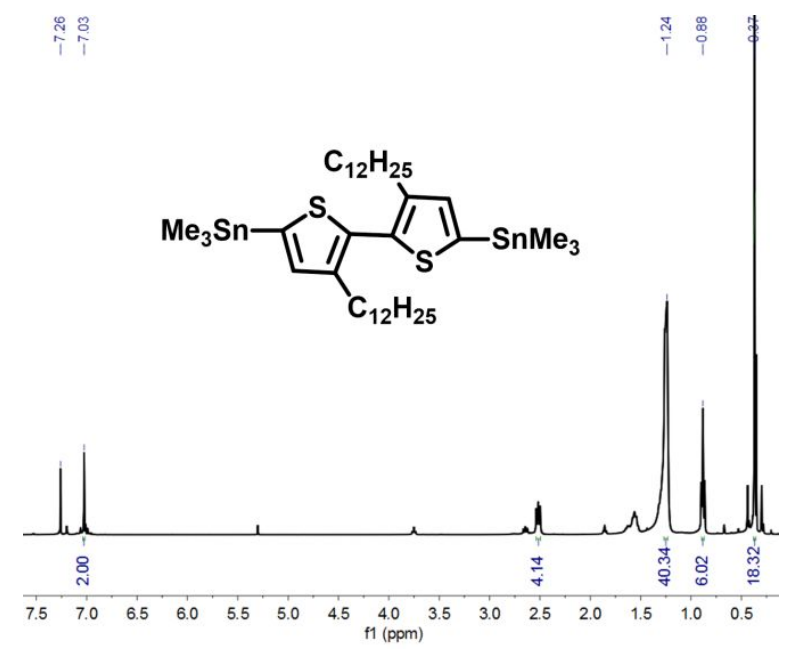

Figure S1. ${ }^{1} \mathrm{H}$ NMR spectrum of TT-2Sn.
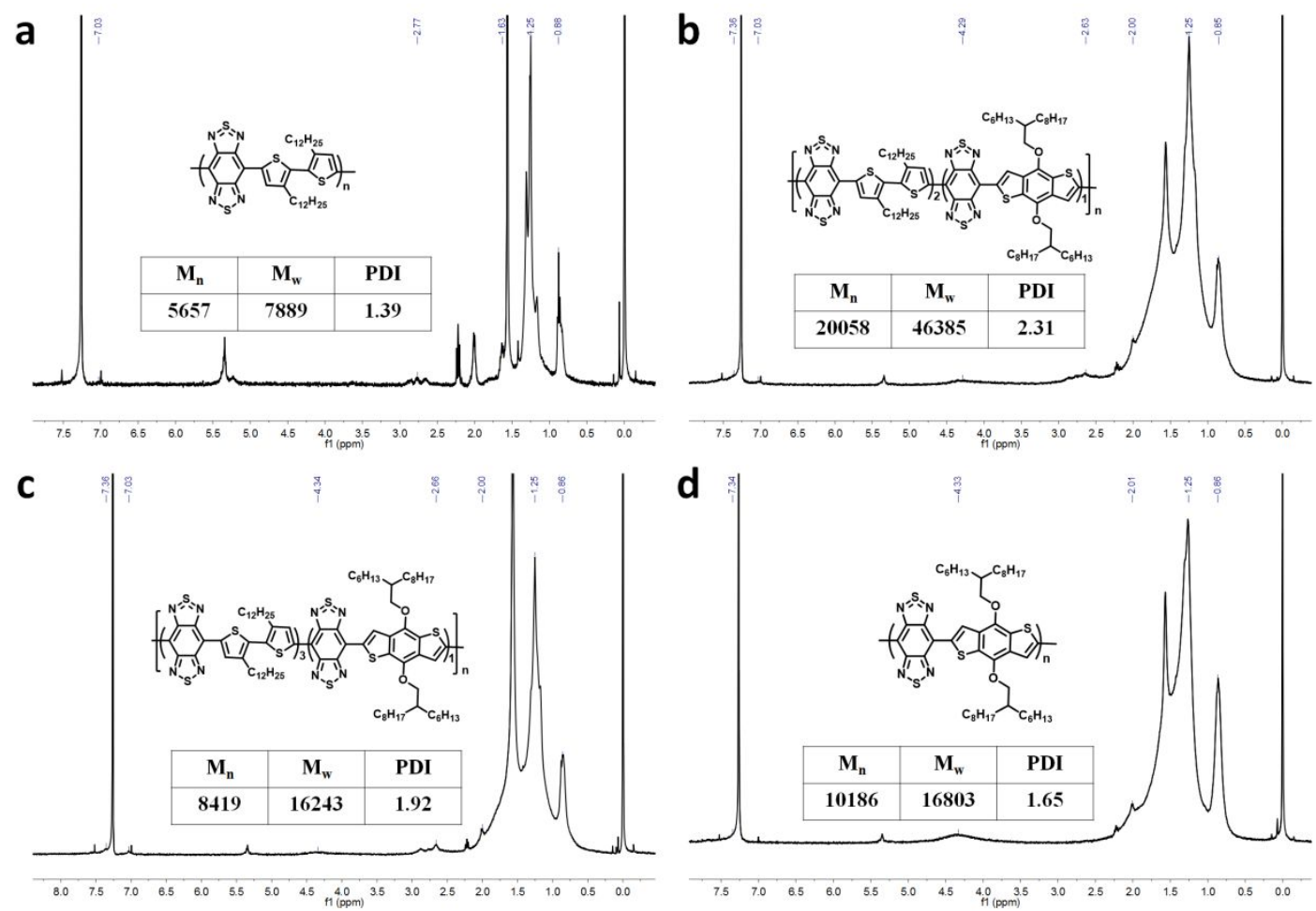

Figure S2. ${ }^{1} \mathrm{H}$ NMR spectra and GPC results (inset) of a) P1, b) P2, c) P3 and d) P4. 


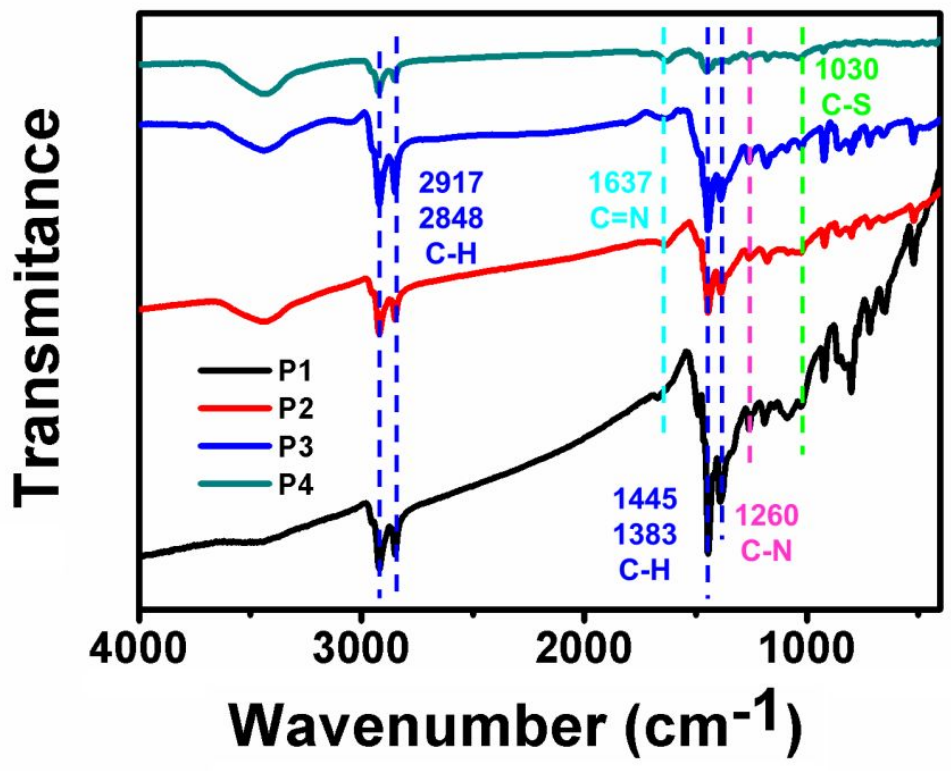

Figure S3. FTIR spectra of P1-P4.

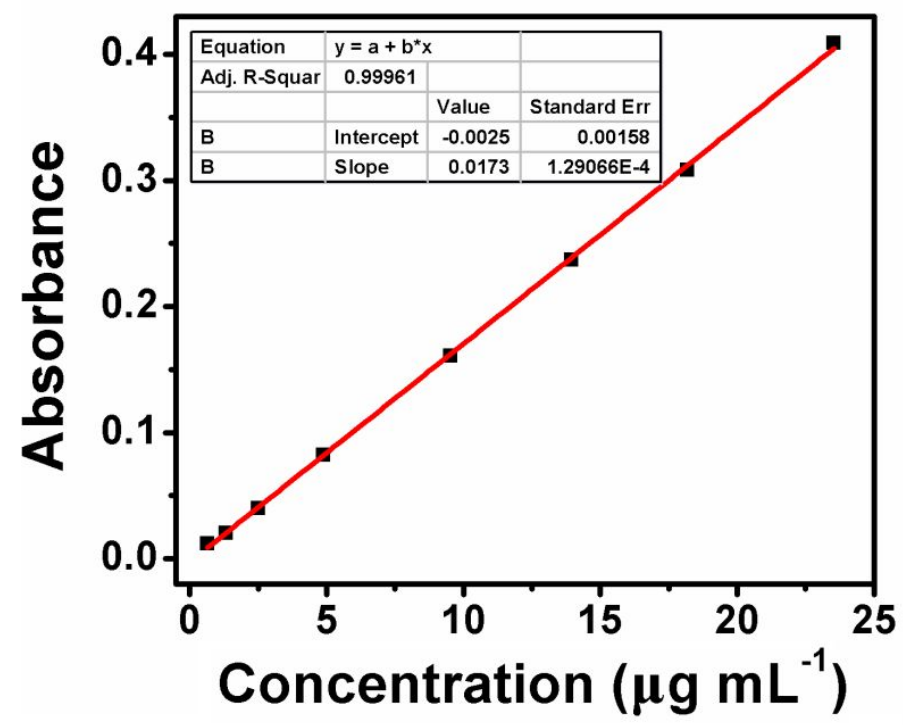

Figure S4. The standard curve of P3 in THF. 

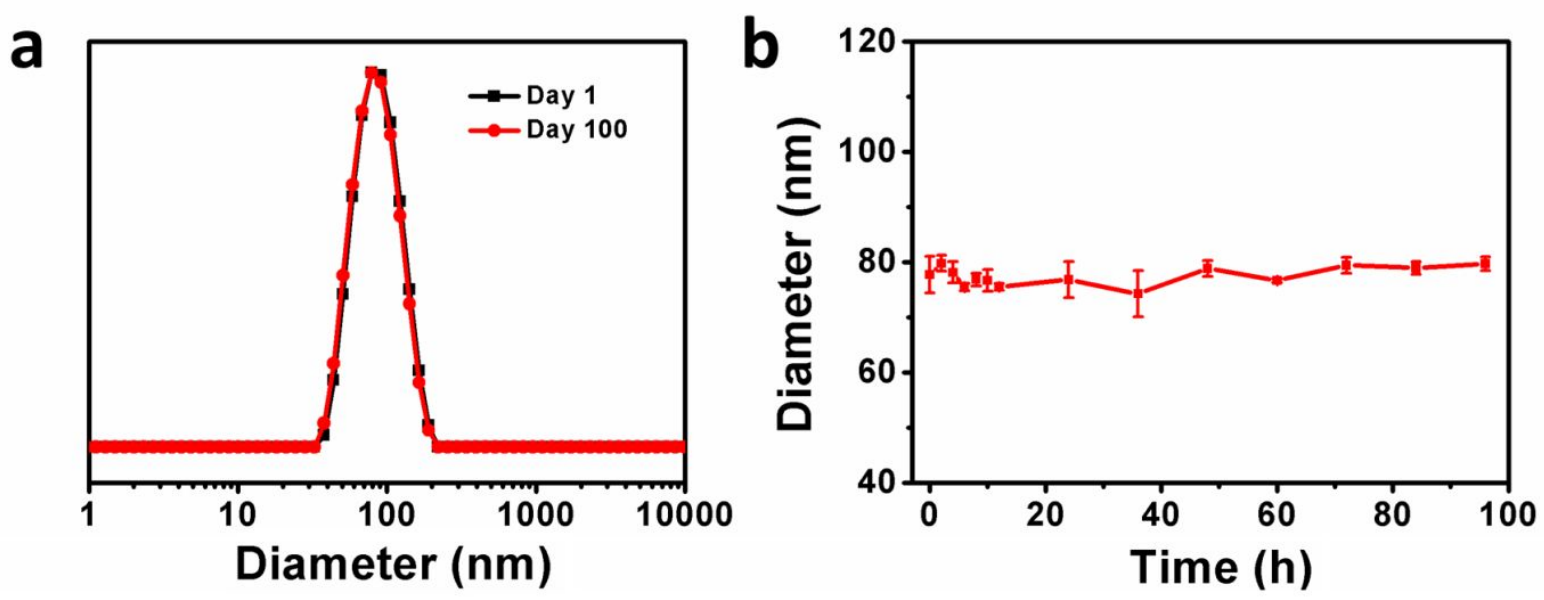

Figure S5. Changes of the diameters of NPs in a) water and b) PBS containing $10 \%$ FBS as a function of time measured by DLS.

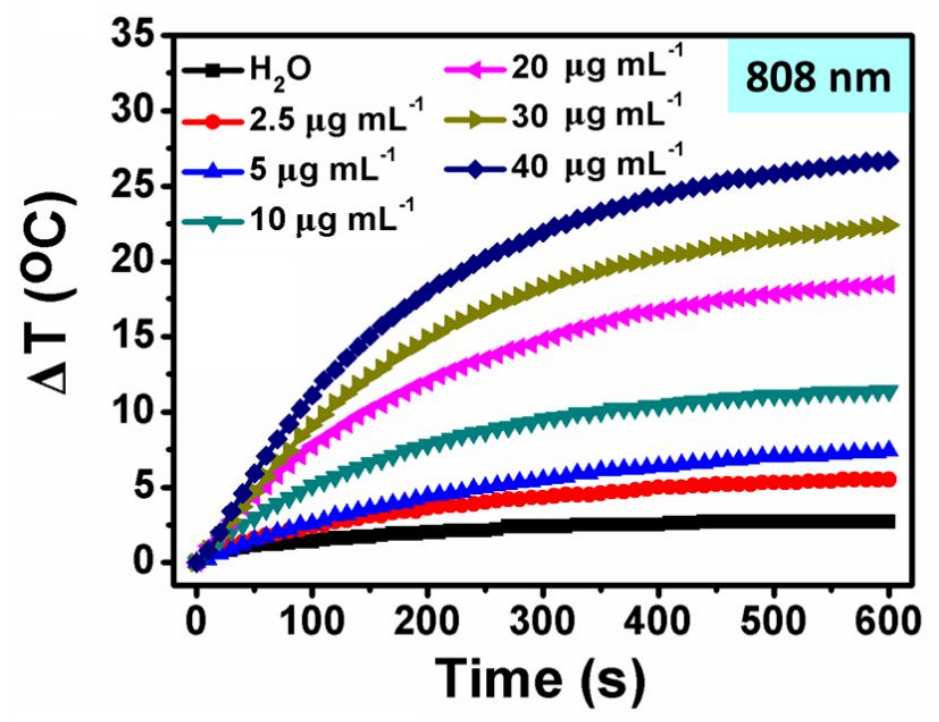

Figure S6. Photothermal conversion behavior of NPs at various concentrations under $808 \mathrm{~nm}$ laser irradiation $\left(1.0 \mathrm{~W} \mathrm{~cm}^{-2}\right)$. 


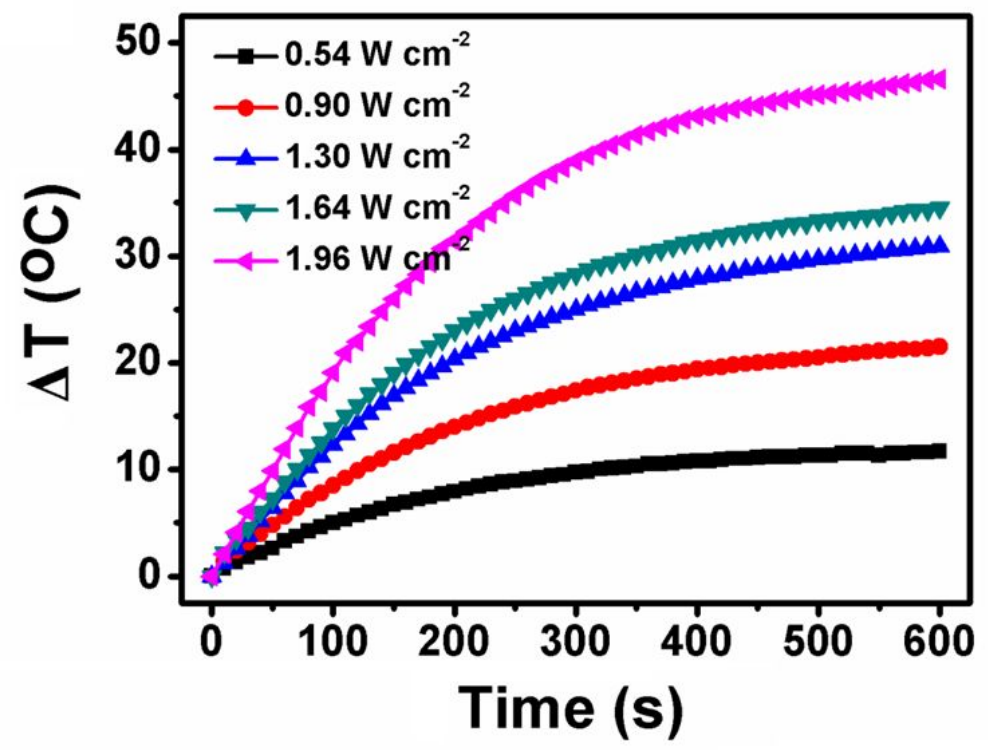

Figure S7. Photothermal conversion behavior of NPs $\left(10 \mu \mathrm{g} \mathrm{mL}^{-1}\right)$ under $1064 \mathrm{~nm}$ laser irradiation by varying power densities $\left(0.54-1.96 \mathrm{~W} \mathrm{~cm}^{-2}\right)$.
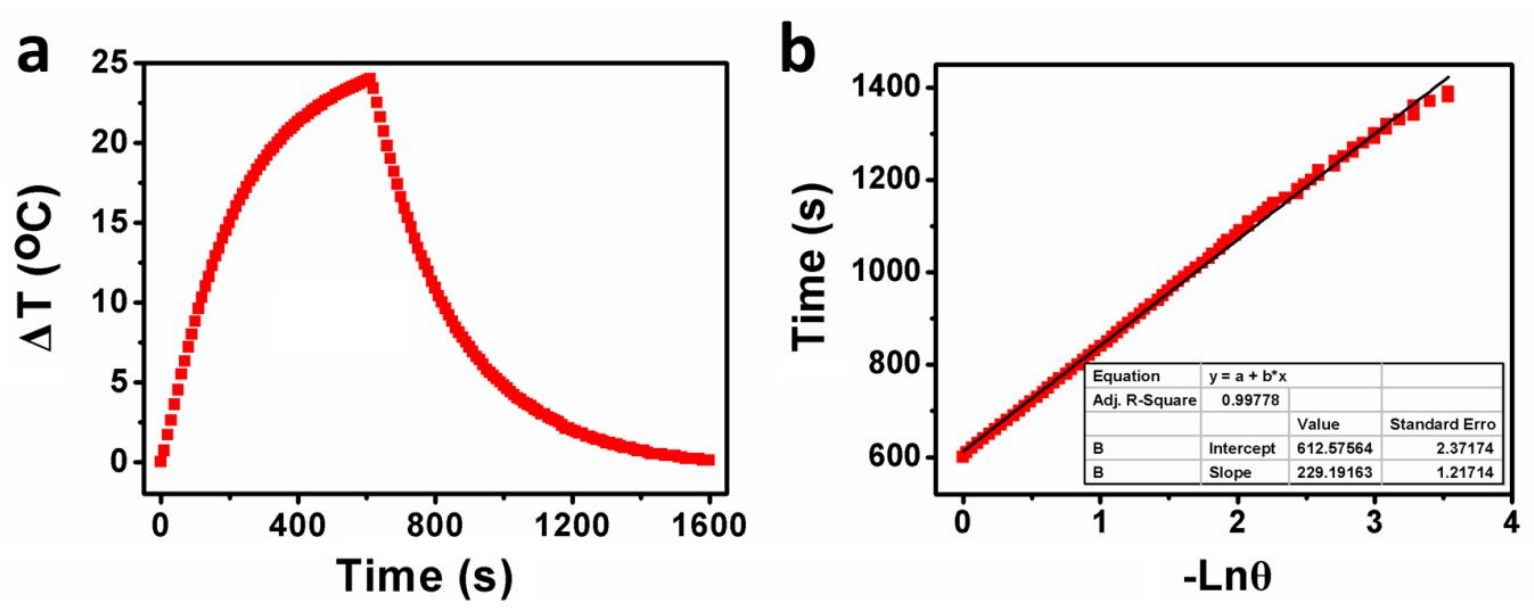

Figure S8. a) The photothermal response of NPs in water with laser irradiation (808 $\mathrm{nm}, 1.0 \mathrm{~W} \mathrm{~cm}^{-2}, 10 \mathrm{~min}$ ) and then the laser was shut off. b) Linear time data versus - $\operatorname{Ln} \theta$ obtained from the cooling period of a). 

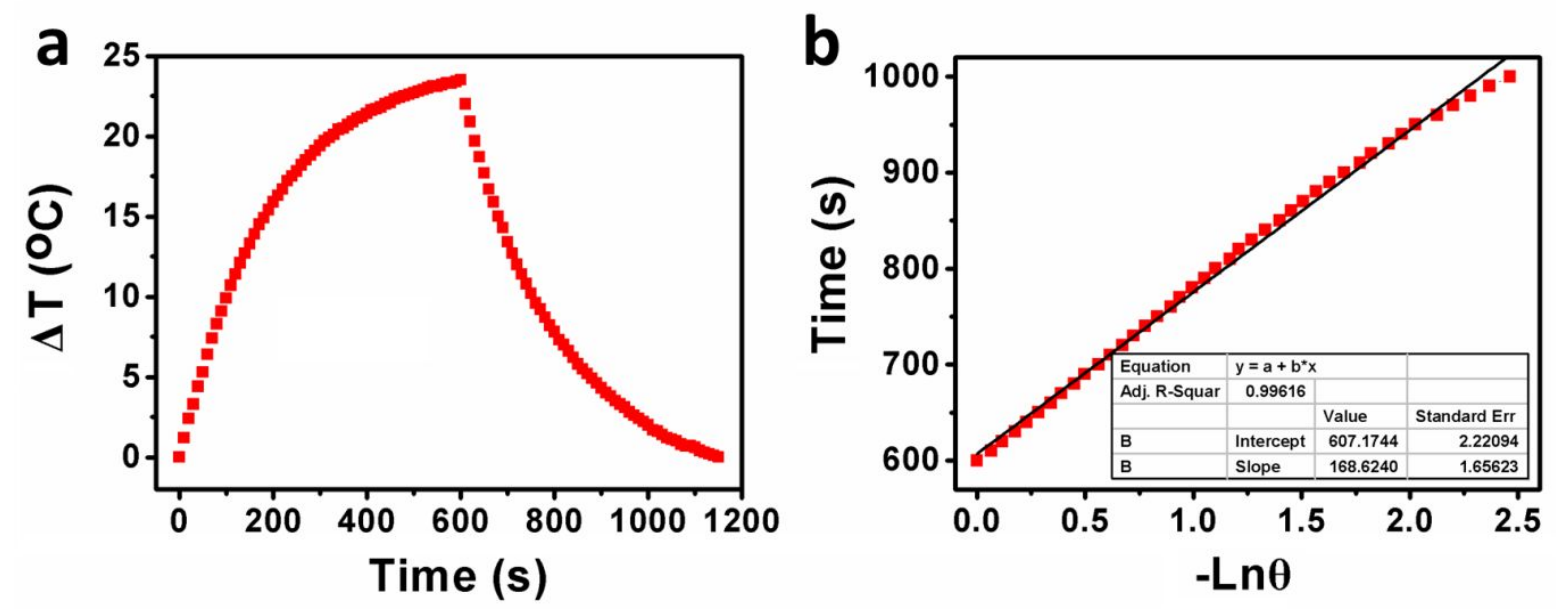

Figure S9. a) The photothermal response of NPs in water with laser irradiation (1064 $\mathrm{nm}, 1.0 \mathrm{~W} \mathrm{~cm}^{-2}, 10 \mathrm{~min}$ ) and then the laser was shut off. b) Linear time data versus -Ln $\theta$ obtained from the cooling period of a).

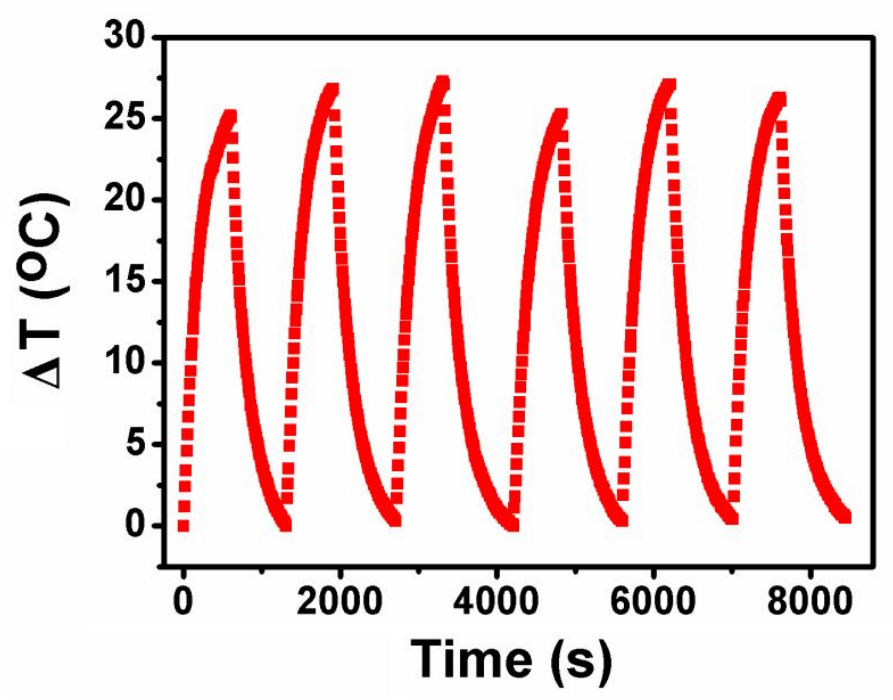

Figure S10. Temperature variations of NPs $\left(20 \mu \mathrm{g} \mathrm{mL}^{-1}\right)$ in water under $1064 \mathrm{~nm}$ laser irradiation over 6 cycles of heating and natural cooling. 


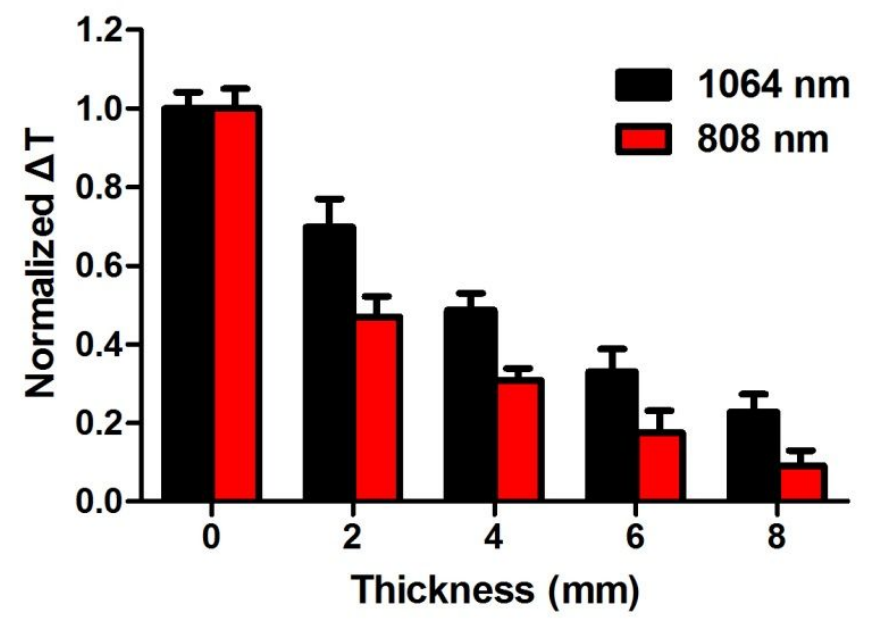

Figure S11. Relative temperature changes of NPs in water upon exposure to 808 and $1064 \mathrm{~nm}$ laser under chicken tissues of varying thicknesses $(0,2,4,6$ and $8 \mathrm{~mm})$.

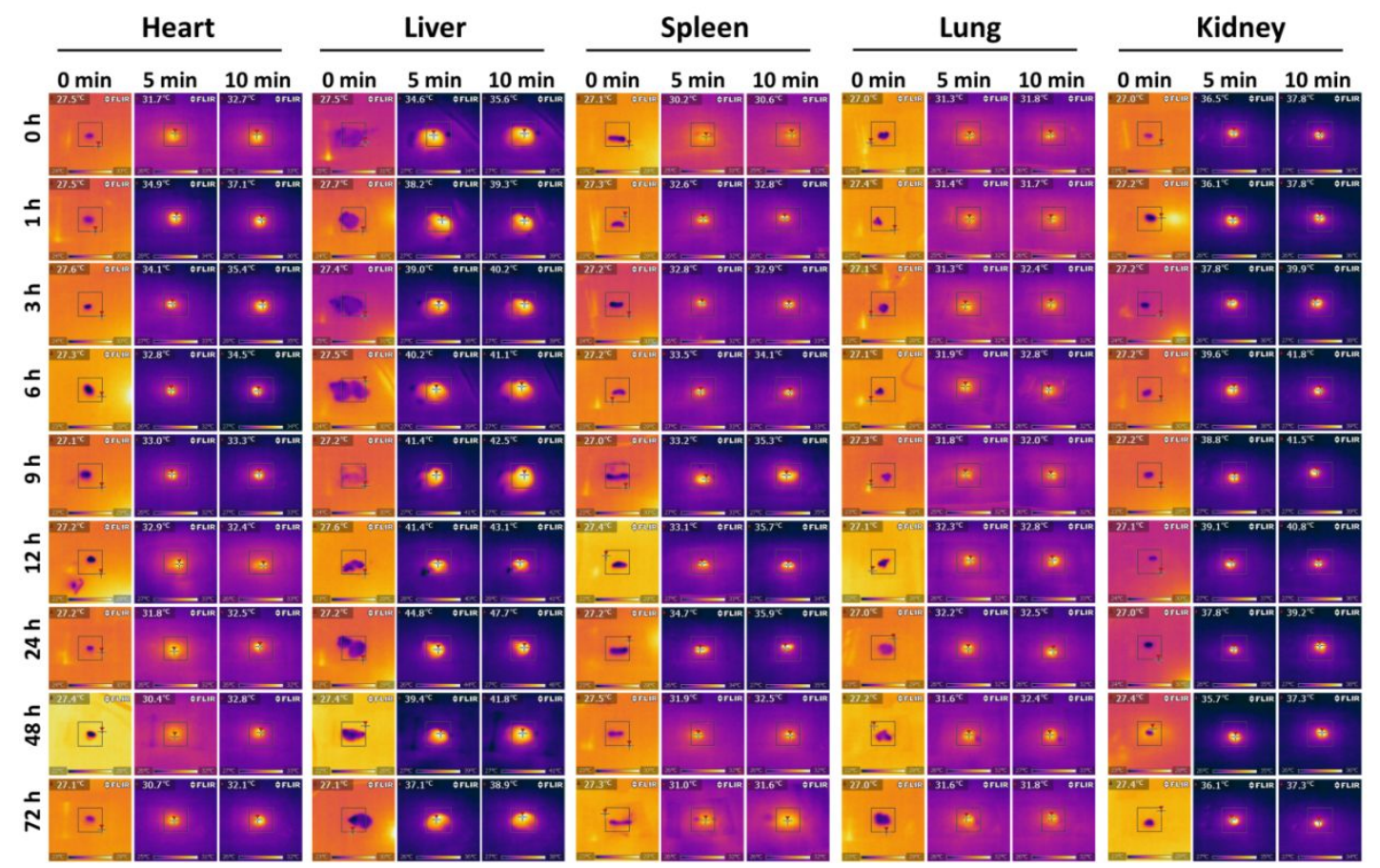

Figure S12. Ex vivo IR images of heart, liver, spleen, lung and kidney of mice injected with NPs intravenously $\left(2.87 \mathrm{mg} \mathrm{kg}^{-1}\right)$ for different time under laser irradiation $\left(1064 \mathrm{~nm}, 1.0 \mathrm{~W} \mathrm{~cm}^{-2}\right)$. 


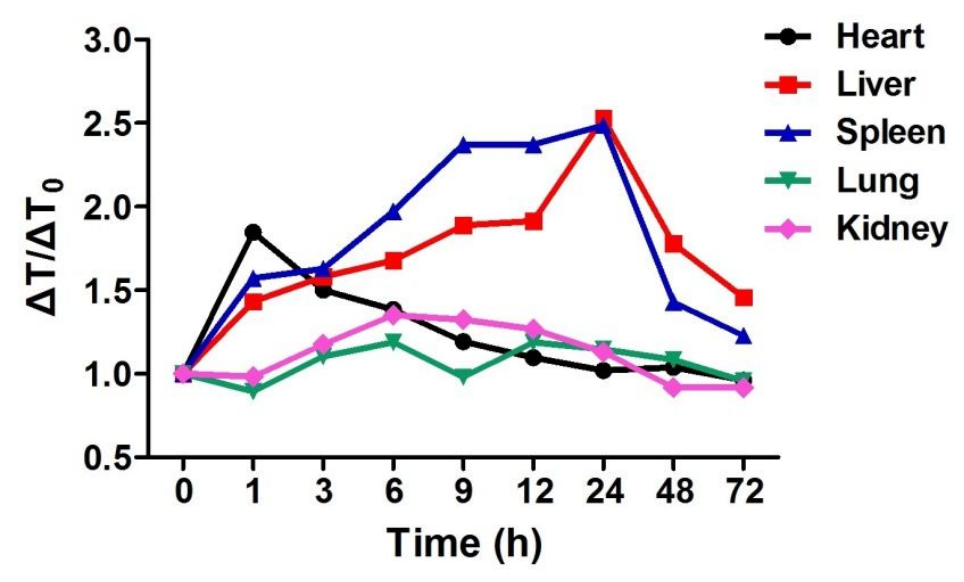

Figure S13. Relative temperature changes of heart, liver, spleen, lung and kidney of mice injected with NPs intravenously $\left(2.87 \mathrm{mg} \mathrm{kg}^{-1}\right)$ for different time under laser irradiation (1064 nm, $\left.1.0 \mathrm{~W} \mathrm{~cm}^{-2}\right)$.

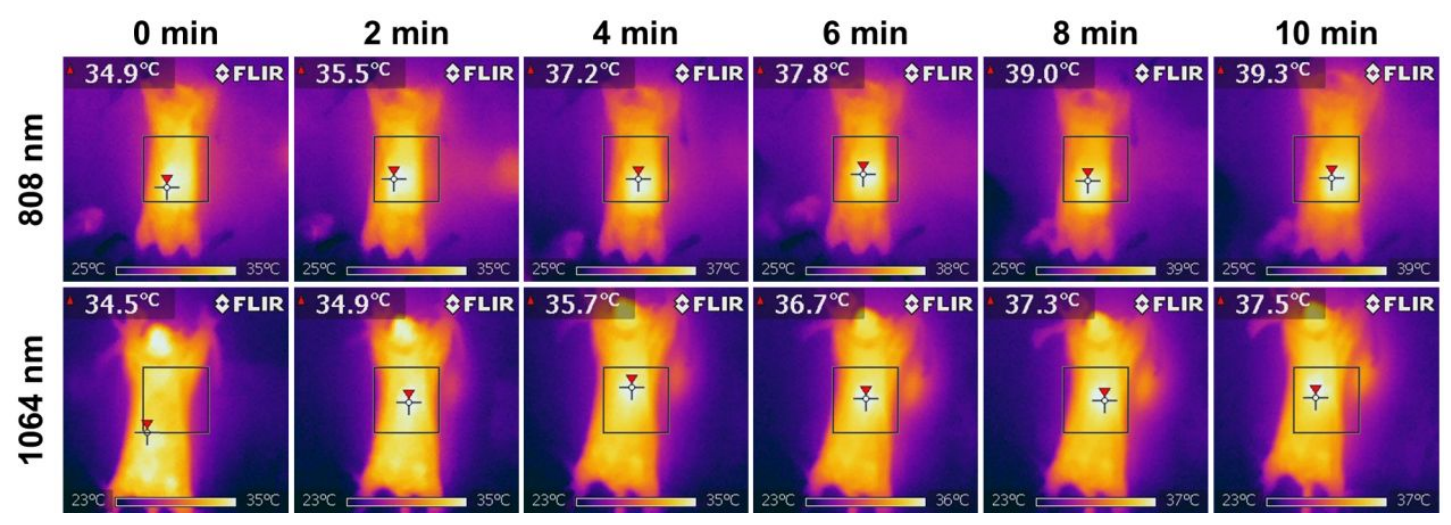

Figure S14. IR images of mice without NPs injection under 808 or $1064 \mathrm{~nm}$ laser irradiation $\left(1.0 \mathrm{~W} \mathrm{~cm}^{-2}\right)$. 


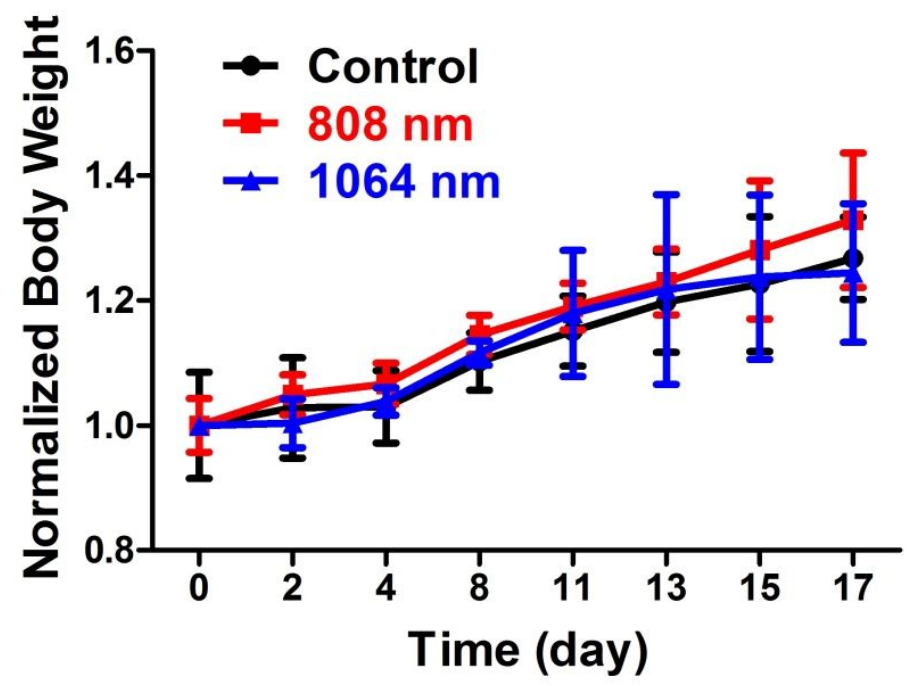

Figure S15. Changes in body weight of tumor-bearing mice after various treatments.

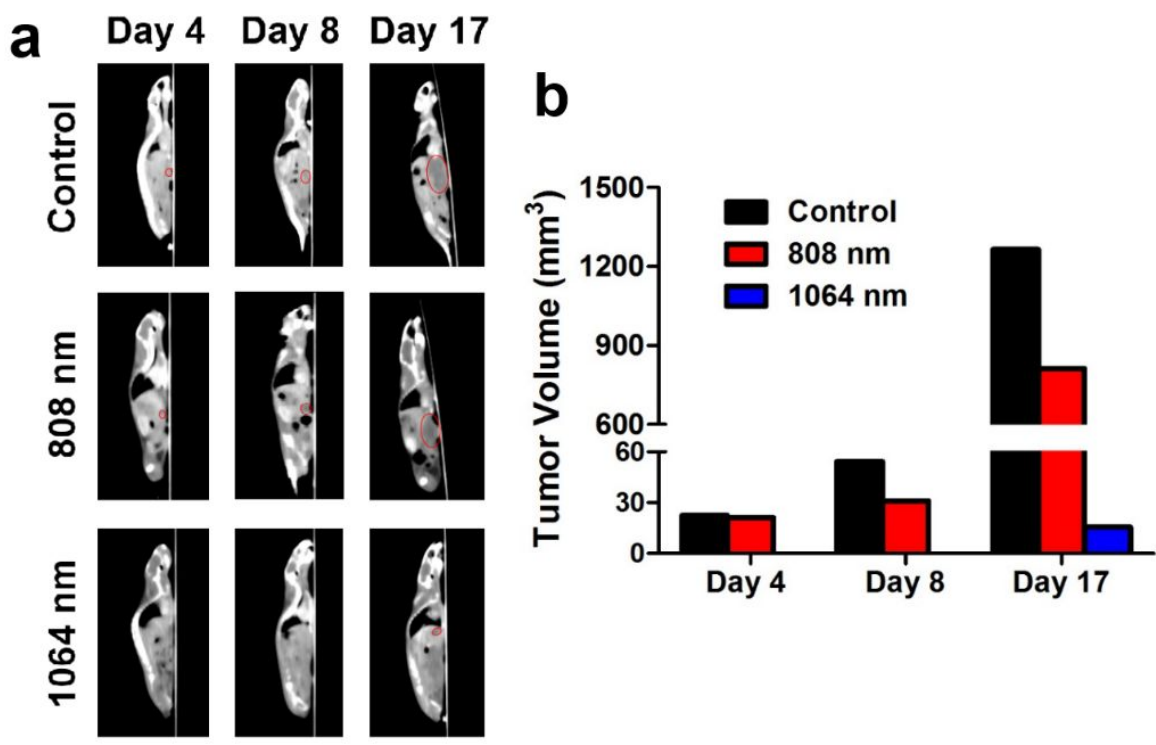

Figure S16. a) CT imaging and b) tumor volumes of mice after different treatments for 4,8 and $17 \mathrm{~d}$. The red circles indicate the tumors in livers. 


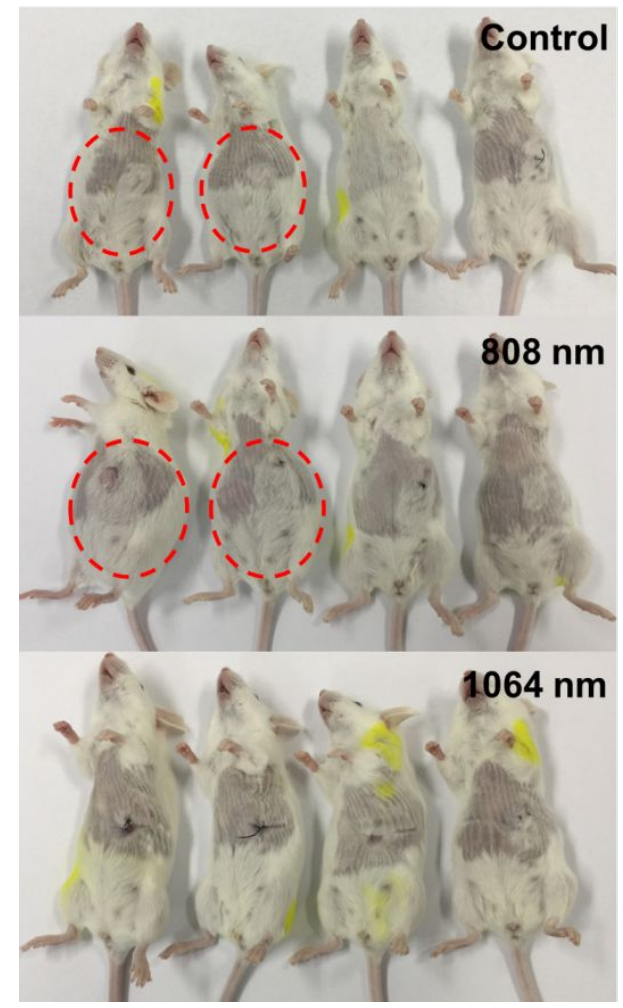

Figure S17. Photos of mice after treatments for $17 \mathrm{~d}$. The red circles indicate the mice with liver ascites.

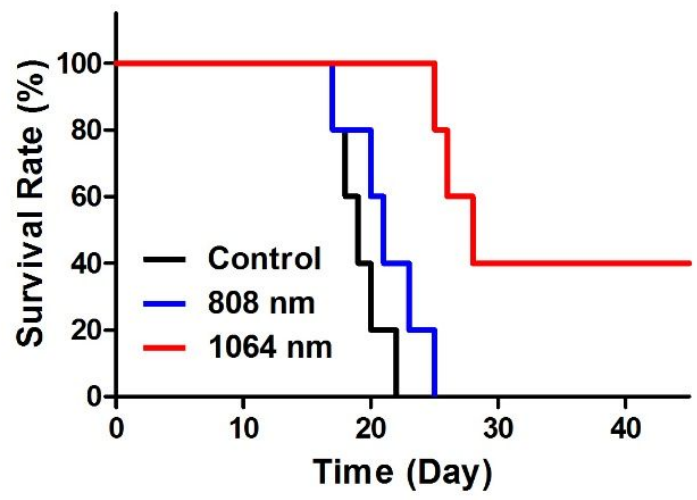

Figure S18. Survival Rates of tumor-bearing mice after various treatments. 